\title{
Visual outcome of cataract surgery in a tertiary care teaching hospital
}

\author{
Murtaza Sameen Junejo ${ }^{1}$, Rebecca², \\ Fahad Feroz Shaikh ${ }^{3}$, Naimatullah Siyal ${ }^{4}$
}

\begin{abstract}
Objectives: To review the visual outcomes after cataract surgery in a tertiary care teaching hospital, Isra University Hyderabad.

Methods: This retrospective clinical study was carried out for six months at Isra University Hyderabad from December 2020-May 2021. Total patients included were 982. The data comprised of patients who underwent cataract surgery from Sept 2018 - Aug 2020. Individuals over 40 years were included and who returned for out-patient appointments. Visual acuity before and six weeks after cataract surgery were noted and categorized according to World Health Organization criteria (i-e Good, Moderate and Poor).. Data analysis was done with the help of SPSS version 22.0.

Results: Out of 982 patients who underwent Phacoemulsification at Isra University Hospital, the operated eyes were 483 right and 499 left respectively. Meanwhile, 966 had good visual acuity six weeks after the surgery, while 16 had moderate visual acuity noted after six weeks.

Conclusion: Clinical audit of cataract surgeries by measuring visual acuity postoperatively is an excellent approach in improving the outcomes and maintaining the good care facilities at a tertiary care hospital.
\end{abstract}

KEYWORDS: Cataract, Clinical Audit, Phacoemulsification, Visual Acuity.

doi: https://doi.org/10.12669/pjms.38.4.5163

How to cite this:

Junejo MS, Rebecca, Shaikh FF, Siyal N. Visual outcome of cataract surgery in a tertiary care teaching hospital. Pak J Med Sci. 2022;38(4):900-903. doi: https://doi.org/10.12669/pjms.38.4.5163

This is an Open Access article distributed under the terms of the Creative Commons Attribution License (http://creativecommons.org/licenses/by/3.0), which permits unrestricted use, distribution, and reproduction in any medium, provided the original work is properly cited.

\section{INTRODUCTION}

Worldwide blindness is mainly caused by cataract and in Pakistan it alone is liable for $51.5 \%$ of blindness, consistent with Pakistan's National Blindness and Visual Defect Survey

1. Dr. Murtaza Sameen Junejo, FCPS

2. Dr. Rebecca, MBBS

3. Dr. Fahad Feroz Shaikh, FCPS, FRCS (GLASGOW), FCPS(VR).

4. Prof. Dr. Naimatullah Siyal, MCPS, MS.

1-4: Department of Ophthalmology,

Isra University Hospital, Hyderabad, Pakistan.

Correspondence:

Dr. Murtaza Sameen Junejo, FCPS.

Department of Ophthalmology,

Isra University Hospital, Hyderabad, Pakistan.

Email: drmurtazasameen@gmail.com

* Received for Publication:

August 11, 2021

* $1^{\text {st }}$ Revision Received:

* $2^{\text {nd }}$ Revision Received:

* Final Revision Accepted:
2002-03. ${ }^{1}$ A treatment for the cataract being the surgical extraction which usually is followed by a lens implantation. A Phacoemulsification is the micro incision suture less procedure for cataract removal worldwide and in developing countries like Pakistan, an extracapsular cataract extraction (ECCE) is also less commonly done.

Recent advances in technology of cataract extraction have made the life of everyone very comfortable. Ophthalmologists now offer patients high quality of lens implants. Following cataract removal, the implantation of intraocular lenses that provide simultaneous near and far correction is now routinely done. ${ }^{2}$ Due to bilateral cataracts 22 million people are blind within the whole world which is predicted to rise to 33 million by 2023. Half of all global blindness is cataract-induced and that is reversible. Safe and predictable cataract surgery 
outcomes are noticed only within the developed world; the rates of post-operative blindness are surprising within the developing world. Cataract surgery may also cause serious complications that can lead to blindness. In developing countries still the old technique of cataract extraction is being followed i-e couching. ${ }^{3-5}$

Clinical audit may be a tool, used not only to watch quality of services provided by doctors but also tells us whether we do it correctly up to the rules or not. The World Health Organization (WHO) has recommended that post-operative visual outcome after cataract surgery should be good (6/6-6/18) in $80 \%$ of cases. At the Layton Rahmatullah Benevolent Trust (LRBT) Eye Hospital, Lahore, a charity health center with a high surgical volume, Malik and colleagues reviewed the visual outcome of cataract surgery. ${ }^{4}$ Good visual outcome after correction was seen in $69.9 \%$ eyes. The authors audited the results of cataract surgery at the Isra University Hospital in Hyderabad to work out the extent to which WHO standards are being met.

\section{METHODS}

This retrospective clinical audit was done over a six month period from December 2020May 2021, and comprised data of patients who underwent cataract surgery from September 2018 to August 2020 after approval from Ethical Research Committee (ERC) Isra University, Hyderabad(IUH/ASST Dean(CS)/05/30). It had been limited to individuals aged over 40 years who had cataract surgery, and who returned for outpatient appointments. Patients excluded were those that had surgery for traumatic cataracts, or who had other ocular procedures like trabeculectomy or associated diabetic retinopathy and age related degeneration, performed at the time of cataract extraction. Visual acuity before and after surgery, and findings on examination were noted upto six weeks postoperatively. Keratometry (k1+
Table-I: Total number of patients.

\begin{tabular}{lcc}
\hline & Frequency & Percent \\
\hline Male & 445 & 45.3 \\
Female & 537 & 54.7 \\
Right Eye & 483 & 49.2 \\
Left Eye & 499 & 50.8 \\
\hline
\end{tabular}

K2) and Amplitude scan (A-Scan) were performed to calculate intraocular lens (IOL) power using SRK T/ II formulae. Systemic comorbidities, mainly diabetes mellitus, hypertension, and ischemic heart disease were ruled out. Topical and/or peribulbar anaesthesia was used before commencement of a surgery. Injection xylocaine $2 \%$ was given in the inferotemporal quadrant and for topical proparacaine $0.5 \%$ eye drops were used. Cataract extraction technique used was phacoemulsification, along with implantation of intraocular lens (IOL). Post-operatively, topical moxifloxacin eye drops and steroidal anti-inflammatory medications were advised. Hypertonic saline 5\% was given only to selected patients with striate keratopathy. Postoperative follow-up was done at day one, after one week, four weeks and six weeks respectively. Data analysis was done with help of SPSS version 22.0. Classification of visual acuity before and after surgery was done by using the WHO guidelines: Good outcome $=6 / 6-6 / 18$; Borderline $=<6 / 18$ $6 / 60$ and Poor $=<6 / 60$.

\section{RESULTS}

Total 982 patients had their cataract surgery at Isra Hospital, out of which there were 537 $(54.7 \%)$ females and $445(45.3 \%)$ males having total mean of \pm 1.55 with SD \pm .498 (Table-I \& II). All patients completed their follow-up criteria. The eyes operated were 483(49.2) right eyes and 499 (50.8) left eyes having total mean value of \pm 1.51 and SD \pm .500 (Table-II). The Visual Acuity before surgery was mean of \pm 2.39 with SD of \pm .487 and after 06 weeks of surgery was \pm 1.02

Table-II: Mean and Standard deviation of VA Before and After Cataract Surgery.

\begin{tabular}{lcccc}
\hline & Gender & Eyes & VA before surgery & BCVA after 06 weeks \\
\hline $\mathrm{n}$ = total number & 982 & 982 & 982 & 982 \\
missing & 0 & 0 & 0 & 0 \\
mean & \pm 1.55 & \pm 1.51 & \pm 2.39 & \pm 1.02 \\
standard deviation & .498 & .500 & .487 & .127 \\
\hline
\end{tabular}


Table-III: VA before surgery.

\begin{tabular}{|c|c|c|}
\hline & Frequency & Percent \\
\hline$<6 / 18-6 / 60$ (Moderate) & 602 & 61.3 \\
\hline$<6 / 60$ (Poor) & 380 & 38.7 \\
\hline \multicolumn{3}{|c|}{ Best corrected VA 06 weeks after surgery } \\
\hline 6/6 - 6/18 (Good) & 966 & 98.4 \\
\hline$<6 / 18-6 / 60$ (Moderate) & 16 & 1.6 \\
\hline$<6 / 60$ (Poor) & 0 & 0 \\
\hline
\end{tabular}

and SD was \pm .127 shown in Table-II. Preoperative VA was moderate in $61.3 \%$ patients andpoor in $38.7 \%$ patients. Meanwhile, VA after 06 weeks of phacoemulsification was good in 966 (98.4\%) and moderate in $16(1.6 \%)$ of patients according to WHO criteria (Table-III).

\section{DISCUSSION}

According to WHO database; cataract surgery is one among the foremost commonly performed ophthalmic surgeries worldwide, and its frequency will increase due to environmental and lifestyle changes in upcoming years. As cataract technique and technology advances, one has to demonstrate improving outcomes. To the best of our knowledge such a study with detailed surgical outcomes has not been conducted in our population. ${ }^{6,7}$

Overall, Pre-operative BCVA, consistent with WHO guidelines, was moderate in 602 (61.3\%) patients and poor in $380(38.7 \%)$ compared with $43 \%$ reported by the United Kingdom Cataract National Dataset Electronic Multicentre Audit (CNDEMA). ${ }^{8}$ There is a much bigger correlation of systemic comorbidity with cataract surgery. Many systemic conditions can dramatically reduce potential for VA after surgery. The prevalence of preoperative recorded co-pathology is a smaller amount than those published in CNDEMA which was $71.5 \%$. The common pre-operative ocular co-morbidity found in CNDEMA was proliferative diabetic retinopathy, glaucoma, corneal degeneration and age- related macular degeneration (ARMD). ${ }^{8}$ In contrast, we did not include the patients which had systemic comorbidity in this study., ${ }^{9,10}$

In our study surgery was performed by highly qualified surgeons. In our tertiary care hospital, the peribulbar anesthesia is the most common route for anaesthesia in contrast with the NEON and PORT studies where the topical anaesthesia was the standard one, followed by peribulbar blocks that were given occasionaly. ${ }^{8,9}$
The source of data collection was manual as compared to electronic method of data collection done at various centres of NHS hospital which helps in systemic evaluation of various diseases record. ${ }^{10,11}$ It has been observed that akinetic anaesthesiamay reduce posterior capsule rupture (PCR) rates. The superiorty of anesthesia is not mentioned in literature in terms of PCR. ${ }^{12}$ In our study, Superiorty of akinetic anaesthesia over kinetic one was not observed. Cataract surgery in microophthalmic eye has significant results as studied in Al-Ibrahim eye hospital. ${ }^{13}$

It is observed that superior limbal incisions induce much more corneal astigmatic change than temporal incisions due to against the rule astigmatism. ${ }^{13-17}$ We did not calculate the amount of astigmatism in our study.

Another study conducted at Singapore National eye centre revealed significance of femtosecond assisted laser cataract surgery, which revealed better visual outcomes at 6 weeks. ${ }^{10,13}$ On the contrary, constellation machine was used in all surgeries at our hospital.

By doing clinical audit we calculate some important facts that are usually missed like steps of surgery, instruments used and time taken. ${ }^{18-21}$ So, for the betterment of surgical outcomes, audit and re audit should be conducted. ${ }^{22-25}$

Postoperative VA was recorded for 982 (100\%) eyes. After cataract surgery, $966(98.4 \%)$ eyes had good VA compared with pre-operative measurements. There have been 16(1.6\%) eyes of patients who's VA was moderate according to WHO criteria. The most common reason for moderate BCVA was posterior capsule rupture and cystoids macular oedema.

Limitations of this study: We did not calculate surgically induced astigmatism, Corneal degenerations, systemic co-pathology, postoperative retinal detachment and vitrous loss. BCVA was checked on snellen chart instead of LogMAR, which is the standard one used commonly due to its reliability. We also did not include patients with diabetic retinopathy and age related macular degeneration and time taken during surgeries.

\section{CONCLUSION}

The surgeries performed at tertiary care hospital had a good outcome as they were performed by highly skilled surgeons. Such audit can be helpful in improving surgeons surgical skills, frequent visits 
prevents patients from devastating complications like endophthalmitis and also it improves the quality of small incision sutureless surgery.

\section{Disclosure: None.}

\section{Grant Support E Financial Disclosures: None.}

\section{REFERENCES}

1. Jadoon M Z, Dineen B, Bourne RRA, Shah SP, Khan MA, Johnson GJ, et al. Prevalence of Blindness and Visual Impairment in Pakistan. The Pakistan National Blindness and Visual Impairment Survey. Invest Ophthalmol Visual Sci. 2006(47):4749-4755. doi: 10.1167/iovs.06-03740

2. Meyer JJ, Vellara HR, Bhikoo R, Sefo LA, Lolokabaira S, Murray NL, et al. Improved refractive outcomes of small incision Extracapsular cataract surgery after implementation of a biometry training course. Middle East Afr J Ophthalmol. 2019;26(1):17-22. doi: 10.4103/meajo.MEAJO_3_18

3. Chippa SA, Junejo MK. Outcomes of cataract surgery at teaching hospital at Karachi. J Pak Med Assoc. 2018;68(1):76-80.

4. Shaheen MS, AbouSamra Amir, Helalay HA, Said A,Elmassry A. Comparison between refractive outcomes of femtosecond laser - assisted cataract surgery and standard phacoemulsification. BMC Ophthalmol. 2020;20(1):1. doi: 10.1186/s12886-019-1277-9

5. Roberts V T, Lawless M, Bali J S, Hodge C, Sutton G. Surgical outcomes and safety of femtosecond laser cataract surgery: a prospective study of 1500 consecutive cases. Ophthalmology. 2013;120(2):227-233. doi: 10.1016/j. ophtha.2012.10.026

6. Chen H, Hyatt T, Afshari N. Curr Opin Ophthalmol. 2014;25(1):49-53. doi: 10.1097/ICU.0000000000000019

7. Yangzes S, Seth GN, Singh R, Gupta CP, Jinagal J, Pandav SS, et al. Indian J Ophthalmol. 2019;67(4):490-495. doi: 10.4103/ijo.IJO_846_18

8. Sparrow JM, Taylor H, Qureshi K, Smith R, Birnie K, Johnston RL. UK EPR user group. The cataract national dataset electronic multi-centre audit of 55,567 operations: Risk indicators for monocular visual acuity outcomes. Eye (Lond). 2012;26:821-826. doi: 10.1038/ eye.2012.51

9. Yu Y, Chen X, Hua H, Wu M, Lai K. Comparative outcomes of femtosecond laser-assisted cataract surgery and manual phacoemulsification: A six-month follow-up. Clin Exp Ophthalmol. 2016;44(6):472-480.doi: 10.1111/ceo.12695

10. Chee SP, Yang Y, Ti SE. Clinical outcomes in first two years of femtosecond laser-assisted cataract surgery. Am J Ophthalmol. 2015;159(4):714-719. doi: 10.1016/j. ajo.2015.01.016

11. Chew FLM, Qurut SE, Hassan I, Lim ST, Ramasamy S, Rahmat J. Pediatric cataract surgery in hospital kuala Lumpur: A 5-year review of visual outcomes. Med J Malaysia. 2019;74(1):15-19.

12. Lai FH, Lok JY, Chow PP, Young AL. Clinical outcomes of cataract surgery in very elderly adults. J Am GeriatrSoc. 2014;62:165-170. doi: 10.1111/jgs.12590

13. Majid S, Ateeq A,Bukhari S,Hussain M. Outcomes of cataract surgery in microophthalmia. Pak J Med Sci. 2018;34(6):15251528. doi: 10.12669 / pjms.346.14622
14. Gomez ML. Measuring the quality of vision after cataract surgery. Curr Opin Ophthalmol. 2014;25:3-11. doi: 10.1097/ ICU.000000000000011

15. Tabin G, Chen M, Espandar L. Cataract surgery for the developing world. Curr Opin Ophthalmol. 2008;19:55-59. doi: 10.1097/ICU.0b013e3282f154bd

16. Gale RP, Saldana M, Johnston RL, Zuberbuhler B, McKibbin M. Benchmark standards for refractive outcomes after NHS cataract surgery. Eye (Lond). 2009;23:149-152. doi: 10.1038/ sj.eye. 6702954

17. S Bhavana, AG Robin, Arora T, Antony T, Vajpayee RB. Techiques of anterior capsulotomy in cataract surgery. Indian J Ophthalmol. 2019;67(4):450-460. doi: 10.4103/ijo. IJO_1728_18

18. Kelkar A, Kelkar J, Mehta H, Amoaku W. Cataract surgery in diabetes mellitus: A systemic review. Indian J Ophthalmol. 2018;66(10):1401-1410. doi: 10.4103/ijo.IJO_1158_17

19. Awasthi N, Guo S, Wagner BJ. Posterior capsule opacification: A problem reduced but not yet eradicated. Arch Ophthalmol.2009;39:201-206. doi: 10.1001/ archophthalmol.2009.3

20. Pascolini D, Mariotti SP. Global estimates of visual impairment: 2010. Br J Ophthalmol. 2012;96(5):614-618. doi: 10.1136/bjophthalmol-2011-300539

21. Menda SA, Driver TH, Neiman AE, Naseri A, Stewart JM. Return to the operating room after resident-performed cataract surgery. JAMA Ophthalmol. 2018;33(10):210-214. doi: 10.1080/08820538.2016.1208760

22. Chen M, Lamattina KC, Patrianakos $T$, Dwarakanathan $\mathrm{S}$. Complication rate of posterior capsule rupture with vitreous loss during phacoemulsification at a Hawaiian cataract surgical center: a clinical audit. Clin Ophthalmol. 2014;8:375-378. doi: 10.2147/OPTH.S57736

23. Staropoli PC, Gregori NZ, Junk AK, Galor A, Goldhardt R, Goldhagen $\mathrm{BE}$, et al. Surgical simulation training reduces intraoperative cataract surgery complications among residents. Simul Healthc. 2018;13(1):11-15. doi: 10.1097/ SIH.0000000000000255

24. McCannel CA, Reed DC, Goldman DR. Ophthalmic surgery simulator training improves resident performance of capsulorhexis in the operating room. Ophthalmology. 2013;120(12):2456-2461. doi: 10.1016/j.ophtha.2013.05.003

25. Moore DB, Slabaugh MA. Surgical outcomes and cost basis for resident-performed cataract surgery in an uninsured patient population. JAMA Ophthalmol. 2013;131(7):891-897. doi: 10.1001/jamaophthalmol.2013.202

\section{Authors' Contribution:}

JMS: Conceived, designed and did statistical analysis \& editing of manuscript, is responsible for integrity of research.

JMS, R, SFF: Did data collection and manuscript writing.

SN: Did review and final approval of manuscript. 